\title{
Optimization of Turbidity and COD Removal from Pharmaceutical Wastewater by Electrocoagulation. Isotherm Modeling and Cost Analysis
}

\author{
Hadjira Kermet-Said*, Nadji Moulai-Mostefa \\ Materials and Environmental Laboratory, Faculty of Sciences and Technology, \\ University of Medea, Ain D'heb, Medea 26001, Algeria
}

Received: 10 October 2014

Accepted: 29 December 2014

\begin{abstract}
The present work was conducted to optimize operating parameters for electrocoagulation treatment of a pharmaceutical effluent. Chemical oxygen demand (COD) and turbidity removals were monitored for each experiment since they are good indicators of wastewater quality. The effects of three parameters such as $\mathrm{pH}$ (4-10), current density $\left(\mathrm{i}=20-80 \mathrm{~mA} / \mathrm{cm}^{2}\right)$, and time of reaction $(\mathrm{t}=10-30 \mathrm{~min})$ were evaluated using a response surface methodology (RSM) and in particular a full factorial central composite face-centered (CCF) design. The obtained experimental data were fit to a second-order polynomial equation using multiple regressions and were also analyzed by variance analysis (ANOVA). The contour plots derived from the mathematical models were applied to determine the optimal conditions ( $\mathrm{pH}$ of 5.31 , current density of $46.83 \mathrm{~mA} / \mathrm{cm}^{2}$, and electrolysis time of $17.99 \mathrm{~min}$ ). Under these conditions, the experimental COD and turbidity removals were found equal to 75.64 and $96.34 \%$, respectively, which were in agreement with the values predicted by the models. The electrocoagulation mechanism was modeled using Freundlich and Dubinin-Radushkevich isotherms. The obtained results showed that the Freundlich isotherm correctly predicted the experimental data. Operating costs included energy and electrode consumption as performed for the process of treatment. It was noted that the general cost varied from 0.1053-2.8289 US\$ for current densities ranging from $20-80 \mathrm{~mA} / \mathrm{cm}^{2}$ and electrolysis times from 10-30 min. Under optimal conditions, the general cost was found equal to $0.8113 \mathrm{US} \$ / \mathrm{m}^{3}$.
\end{abstract}

Keywords: pharmaceutical effluent, electrocoagulation, COD, turbidity, optimization, RSM, isotherm adsorption, operating cost

\section{Introduction}

Pharmaceutical industries generate a lot of waste products whose presence in the aquatic environment poses serious problems [1,2]. It should be noted that tons of different classes of drugs are present in the environment, which are

*e-mail: hadjira_8@yahoo.fr used and extracted through wastewater and sewage treatment plants $[3,4]$.

The treatment of pharmaceutical effluents and disposal of residual compounds is generally quite complex. Each effluent may have particular characteristics that pose specific problems for treatment [5]. The traditional methods of treatment are essentially biological and physiochemical processes [6-8]. However, these techniques have shown 
limited success for the treatment of pharmaceutical wastewater due to the nature and composition of pharmaceutical effluents. Therefore, other technologies have been explored with the aim to further reduce the concentration of pharmaceutical contaminants. These technologies include membrane separation [9], advanced oxidation technology [10], and electrochemical techniques such as electroflotation and electrocoagulation [11, 12]. Electrocoagulation (EC) has shown the potential to largely overcome the drawbacks of conventional processing techniques.

The EC process is characterized by simple and easy equipment and short operating time without added chemicals. In addition, the benefits of EC compared to conventional chemical coagulation include the reduction of acidification of wastewater and salinity, low doses of coagulant, and the possibility of automating the treatment system [13]. It was reported that EC has been successfully applied for the treatment of wastewater containing different types of contaminants $[14,16]$.

Various researchers have described the treatment of pharmaceutical wastewaters by electrochemical processes. Jain et al. [17] applied the electrochemical method for the degradation of pharmaceutical azo dye amaranth in wastewater on activated carbon fiber (ACF) electrodes. Dominguez et al. [18] studied the degradation of real pharmaceutical effluent by an electrochemical process with a BDD anode regarding the effect of two operating conditions, such as current density and flow rate at various residence times. Brillas and Sires [19] presented an overview on the electrochemical methods devised for the treatment of pharmaceutical residues from both synthetic solutions and real pharmaceutical wastewaters. Farhadi et al. [20] compared electrocoagulation (EC), photoelectrocoagulation, peroxielectrocoagulation, and peroxi-photoelectrocoagulation processes used for the removal of chemical oxygen demand (COD) from pharmaceutical wastewater. Boroski et al. [21] applied electrocoagulation using iron electrodes followed by photocatalysis for the treatment of effluents from pharmaceutical and cosmetic factories.

EC is an electrochemical treatment method using sacrificial anodes resulting in the production of active coagulants. In this process, many mechanisms are used to remove pollutants from the aqueous effluents. Anodic oxidation and production of adsorbents (hydrated aluminum hydroxides in the case of aluminum electrodes) occurred simultaneously with cathodic reactions and the evolution of hydrogen gas responsible of absorbent flotation. The metal hydroxides that formed have a large surface and quickly adsorb organic products. Consequently, the formed flocs can be removed by gas flotation or sedimentation.

For a better experimental approach, statistical techniques were preferred for the identification of optimal combination of factors and their interactions. These techniques present the advantages to reduce time and study costs [22]. Response surface methodology (RSM) is a statistical method used for the design of experiments and optimization where the experimental responses are fitted to quadratic functions [23]. RSM was successfully used in the modeling and optimization of wastewater treatment processes [24, 25].
Table 1. Physicochemical characteristics of the pharmaceutical effluents.

\begin{tabular}{|c|c|}
\hline Parameter & Value \\
\hline $\mathrm{pH}$ & 6.46 \\
\hline Conductivity $(\mu \mathrm{S} / \mathrm{cm})$ & 784 \\
\hline Turbidity $(\mathrm{NTU})$ & 48.60 \\
\hline $\mathrm{COD}(\mathrm{mg} / \mathrm{L})$ & 525.51 \\
\hline
\end{tabular}

Table 2. Factors and their levels.

\begin{tabular}{|c|c|c|c|}
\hline Factor & Significance & Experimental Field & Unit \\
\hline $\mathrm{X}_{1}$ & $\mathrm{pH}$ & $4-10$ & - \\
\hline $\mathrm{X}_{2}$ & Current density & $20-80$ & $\mathrm{~mA} / \mathrm{cm}^{2}$ \\
\hline $\mathrm{X}_{3}$ & Time & $10-30$ & $\mathrm{~min}$ \\
\hline
\end{tabular}

In this study, electrocoagulation was applied for the treatment of pharmaceutical wastewater using aluminum electrodes. The ions generated from the dissolution of aluminum are used as coagulants for the removal of COD and turbidity. The study was conducted to test the hypothesis that electrocoagulation can be optimized for the three variables usually needed for wastewater treatment ( $\mathrm{pH}$, current density, and treatment time). The efficiency of COD and turbidity removals was optimized using RSM and in particular a full factorial central composite face centered (CCF) design. For the description of the adsorption mechanism in terms of COD, Freundlich and Dubinin-Radushkevich isotherms have been applied. Also operating cost (energy and electrode consumptions) during the process of electrocoagulation were calculated.

\section{Material and Methods}

\section{Materials}

The effluent used in this study was obtained from a pharmaceutical factory (Medea, Algeria) which is a manufacturing unit of oral and injectable pharmaceutical products (antibiotics) that include $\beta$-lactam antibiotic derivatives, namely penicillin (ampicillin, oxacillin, and amoxicillin), and tetracycline antibiotics (chlortetracycline and doxycycline).

The effluent was collected from the recovery tank of a sewage treatment plant downstream of a production line of finished product using the grab sampling technique which is usually done by the manual method. All experiments were carried out on the same sample, which has the same physicochemical characteristics. The reagents used in this work were analytical grade and were used without any further purification. The physicochemical characteristics of the effluents from the pharmaceutical unit are shown in 
Table 3. Experimental data set for CCF design.

\begin{tabular}{|c|c|c|c|c|c|c|c|}
\hline Run & $\mathrm{X}_{1}$ & $\mathrm{X}_{2}$ & $\mathrm{X}_{3}$ & $\begin{array}{c}\mathrm{Y}_{1} \\
\text { Exp }\end{array}$ & $\begin{array}{c}\mathrm{Y}_{2} \\
\text { Exp }\end{array}$ & $\begin{array}{c}\mathrm{Y}_{1} \\
\text { RSM }\end{array}$ & $\begin{array}{c}\mathrm{Y}_{2} \\
\text { RSM }\end{array}$ \\
\hline 1 & 4 & 20 & 10 & 85.51 & 91.45 & 81.26 & 93.46 \\
\hline 2 & 10 & 20 & 10 & 20.01 & 99.82 & 27.88 & 99.73 \\
\hline 3 & 4 & 80 & 10 & 68.05 & 96.23 & 64.87 & 96.47 \\
\hline 4 & 4 & 20 & 30 & 49.17 & 96.43 & 58.96 & 96.38 \\
\hline 5 & 10 & 20 & 30 & 28.32 & 99.82 & 40.89 & 99.90 \\
\hline 6 & 4 & 80 & 30 & 42.54 & 95.69 & 55.56 & 96.46 \\
\hline 7 & 10 & 80 & 30 & 20.01 & 99.25 & 26.45 & 99.69 \\
\hline 8 & 4 & 50 & 20 & 86.93 & 93.64 & 80.95 & 95.14 \\
\hline 9 & 10 & 50 & 20 & 25.56 & 99.59 & 39.70 & 99.89 \\
\hline 10 & 7 & 20 & 20 & 60.41 & 99.67 & 53.06 & 98.54 \\
\hline 11 & 7 & 80 & 20 & 12.73 & 99.50 & 37.64 & 99.93 \\
\hline 12 & 7 & 50 & 10 & 31.92 & 99.85 & 47.90 & 99.01 \\
\hline 13 & 7 & 50 & 30 & 54.40 & 99.16 & 49.75 & 99.09 \\
\hline 14 & 7 & 50 & 20 & 46.16 & 98.67 & 54.98 & 98.87 \\
\hline 15 & 7 & 50 & 20 & 59.34 & 99.46 & 54.98 & 98.87 \\
\hline 16 & 7 & 50 & 20 & 58.52 & 99.31 & 54.98 & 98.87 \\
\hline
\end{tabular}

Table 1. These characteristics were obtained by the standard test methods, followed by the unit of treatment of the factory which include $\mathrm{pH}$, conductivity, COD, and turbidity.

\section{Experimental Device}

The EC apparatus used in this investigation consists of a pair of aluminum electrodes distanced by $1.0 \mathrm{~cm}$. Electrodes were connected to a DC power supplier of $2.5 \mathrm{~A}$ and $30 \mathrm{~V}$ (HPS3025), operating with current density of 20$80 \mathrm{~mA} / \mathrm{cm}^{2}$. Treatment of samples by electrocoagulation was carried out on a batch-type system using $800 \mathrm{~mL}$ of wastewater at different $\mathrm{pH}$ values (4-10) and treatment times $(10-30 \mathrm{~min})$. The levels of process factors were deduced from the preliminary experiments and literature [26-28]. The $\mathrm{pH}$ was adjusted by adding $\mathrm{HCl}$ or $\mathrm{NaOH}$. After EC, the treated liquid was analyzed in terms of COD and turbidity. Removal efficiencies (RE) were determined using Eq. (1):

$$
R E(\%)=\left(X_{i}-X_{f}\right) / X_{i} \times 100
$$

...where the indices ( $i$ and $f$ ) correspond respectively to the initial and final measures.

\section{Analytical Methods}

The $\mathrm{pH}$ of the treated solution was measured using a $\mathrm{pH}$ meter (Metrohm). Electric conductivity was measured using a conductometer (type Mettler Toledo EL 30).
Turbidity was determined using a turbidity meter (model HF Instruments DRT 100B). COD was determined using a thermoreactor (COD Analysis-ECO 6) complying with the standard NF T90-101.

\section{Operating Cost Calculation}

Energy and electrode consumptions are very important economic tools when calculating operating costs for the electrocoagulation process. Other costs such as labor, maintenance, and other provisions are assumed to be fixed and are not included in the calculations [29, 30]. Operating cost (OC) can be calculated by the following relation (Eq. (2)):

$$
O C=X \cdot E_{c}+Y \cdot E_{e l}
$$

...where $E_{c}$ is energy consumption and $E_{e l}$ is electrode consumption for pollution removal. $X$ and $Y$ are the prices of electricity and electrode materials, respectively. The prices obtained from the Algerian market in September 2013 are as follows: $X=0.0423 \mathrm{US} \$ / \mathrm{kWh}$, and $Y=0.3 \mathrm{US} \$ / \mathrm{kg}$ for aluminum.

Energy consumption $\left(E_{c}\right)$ was calculated from the expression:

$$
E_{c}=\frac{U \cdot I \cdot t}{V}
$$

...where $U$ is cell voltage (V), $I$ is current (A), $t$ is time of electrolysis (s), and $V$ is the volume $\left(\mathrm{m}^{3}\right)$ of treated wastewater. 
Table 4. ANOVA results for COD and turbidity removal.

\begin{tabular}{|c|c|c|c|c|c|c|}
\hline Turbidity removal (a) & DF & SS & MS & $\mathrm{F}$ & $\mathrm{p}$ & SD \\
\hline Total & 16 & 153672 & 9604.47 & & & \\
\hline Constant & 1 & 153574 & 153574 & & & \\
\hline Total Corrected & 15 & 97.6406 & 6.50938 & & & 2.55135 \\
\hline Regression & 9 & 94.6715 & 10.5191 & 21.2568 & 0.001 & 3.24331 \\
\hline Residual & 6 & 2.96914 & 0.494857 & & & 0.703461 \\
\hline Lack of Fit & 4 & 2.61708 & 0.654269 & 3.71673 & 0.223 & 0.808869 \\
\hline Pure Error & 2 & 0.35206 & 0.176034 & & & 0.419564 \\
\hline \multicolumn{7}{|l|}{ COD removal (b) } \\
\hline Total & 16 & 42412.7 & 2650.79 & & & \\
\hline Constant & 1 & 34650 & 34650 & & & \\
\hline Total Corrected & 15 & 7762.75 & 517.516 & & & 22.749 \\
\hline Regression & 9 & 6810.18 & 756.687 & 4.76621 & 0.035 & 27.5079 \\
\hline Residual & 6 & 952.565 & 158.761 & & & 12.6 \\
\hline Lack of Fit & 4 & 741.714 & 185.428 & 1.75885 & 0.394 & 13.6172 \\
\hline Pure Error & 2 & 210.851 & 105.426 & & & 10.2677 \\
\hline
\end{tabular}

(a) $\mathrm{R}^{2}=0.970, \mathrm{R}_{\text {adj }}^{2}=0.924$; (b) $\mathrm{R}^{2}=0.877, \mathrm{R}_{\text {adj }}^{2}=0.693$

Values in bold correspond to the probability (p) in which its value is less than $5 \%$

Electrode consumption $\left(E_{e l}\right)$ can be calculated by the relation (Eq. (4)) [29]:

$$
E_{e l}=\frac{I \cdot t \cdot M}{Z \cdot F \cdot V}
$$

...where $I$ is the current (A), $t$ is the time of electrolysis (s), $M$ is the molecular mass of aluminum $\left(26.98 \mathrm{~g} \cdot \mathrm{mol}^{-1}\right), z$ is the number of electrons transferred $(z=3), F$ is Faraday's constant $\left(96500 \mathrm{C} \cdot \mathrm{mol}^{-1}\right)$, and $V$ is the volume $\left(\mathrm{m}^{3}\right)$ of the treated wastewater.

\section{Experimental Design}

A full factorial central composite face-centered (CCF) design was used in order to investigate the influence of the experimental factors and their interactions on COD and turbidity removals and to make predictions for different input values. The CCF design was chosen because it provides relatively high-quality predictions over the entire design space and does not require using points outside the original factor range [31]. This design was used for the optimization of various treatment processes $[32,33]$.

The medium components (independent variables) selected for optimization were $\mathrm{pH}\left(\mathrm{X}_{1}\right)$, current density $\left(\mathrm{X}_{2}\right)$, and time treatment $\left(\mathrm{X}_{3}\right)$. The responses are $\mathrm{Y}_{1}(\%$ of COD removal) and $\mathrm{Y}_{2}(\%$ of turbidity removal $)$. Regression analysis was performed on the data obtained from the experiments. Coding of the variables was done according to the following equation:

$$
x_{i}=\frac{X_{i}-X c p}{\Delta X_{i}}, \quad i=1,2,3 \ldots, k
$$

...where $x_{i}$ is a dimensionless value of an independent variable, $X_{i}$ is a real value of an independent variable, $X_{c p}$ is a real value of an independent variable at the center point, and $\Delta X_{i}$ is a step change of a real value of the variable $i$ corresponding to a variation of a unit for the dimensionless value of the variable $i$.

The original levels for the process factors are shown in Table 2. The experiments were carried out in duplicate, which was necessary to estimate the variability of measurements.

The relationship of the independent variables and the responses were calculated by the second-order polynomial equation (Eq.6):

$$
Y=\beta_{0}+\sum_{i=1}^{4} \beta_{i}+\sum_{i=1}^{4} \beta_{i i} x_{i}^{2}+\sum \sum_{i<j} \beta_{i j} x_{i} x_{j}
$$

...where $Y$ denotes the predicted response; $x_{i}$ refers to the coded levels of the input variables; $\beta_{0}, \beta_{i}, \beta_{i i}$, and $\beta_{i j}$ are the regression coefficients (off set term, main, and quadratic and interaction effects); and $n$ is the total number of designed variables. The coefficient values of Eq. (6) were calculated and tested for their significance [34, 35].

Model fitting and graphical simulations were obtained using Modde-6 software (Umetrics). 


\section{Adsorption Isotherms}

In the case of an aqueous suspension, the solid/liquid equilibrium is studied through the determination of the adsorption isotherm. It shows the variation of the adsorbed quantity $\left(q_{e}\right)$ on a solid according to the balance of the equilibrium concentration of the adsorbable compound $\left(C_{e}\right)$, at a specific temperature. The curves $q_{e}=f\left(C_{e}\right)$ represent the adsorption isotherms, which are determined experimentally. The experimental data can then be correlated with mathematical models representing the best experimental adsorption isotherms in a wide range of concentrations and temperatures. A large number of adsorption isotherm models have been developed by different researchers. Among these isotherms, Langmuir and Freundlich are commonly used for the determination of the maximum adsorption capacity of the material, and the adsorption constant Kads characterizes the adsorbent-adsorbate interactions [36, 37]. From these isotherms, two parameters can be deduced, the equilibrium constant adsorbate-adsorbent and the adsorption energy. Even more recent models of Kiselev and DubininRadushkevich (D-R) are used for the determination of the constant of the formation of the complex between adsorbed molecules and solid surface [37].

In this work two models were employed: Freundlich and Dubinin-Raduskevich isotherms. The first one is empirical and usually gives a very good representation of the experimental results, and the second is generally applied in order to find out the adsorption mechanisms.

The Freundlich equation is based on adsorption on heterogeneous surfaces. It is used in the case of a possible formation of more than one monolayer of adsorption on the surface, and the sites are heterogeneous with different energies of fixation. The isotherm is expressed by the equation:

$$
q_{e}=k_{f} \cdot c_{e}^{1 / n}
$$

This equation can be linearized as follows:

$$
\ln q_{e}=\ln k_{f}+(1 / n) \cdot \ln c_{e}
$$

...where $k_{f}(\mathrm{mg} / \mathrm{L})$ is the Freundlich adsorption constant and $n$ a constant depending on the nature of the adsorbate and temperature $(0.3<n<0.5$ for a good model verification).

The Dubinin-Radushkevich isotherm is generally applied to express the adsorption mechanism with a Gaussian energy distribution onto a heterogeneous surface [38]. The equation is expressed as follows:

$$
q_{e}=q_{m} \exp \left(-\beta \varepsilon^{2}\right)
$$

Eq. 9 can be linearized as:

$$
\ln q_{e}=\ln q_{m}-\beta \varepsilon^{2}
$$

...where $q_{m}$ represents the maximum theoretical capacity of adsorbate adsorbed on the solid surface and $\varepsilon$ corresponds to the Polanyi potential. This potential is given by Eq. 11:

$$
\varepsilon=R \ln (1-(1 / C e))
$$

...where $R, T$, and $C e$ represent the gas constant, absolute temperature, and adsorbate equilibrium concentration, respectively.

The constant $\beta$ represents the adsorption of molecules on the adsorbent following its transfer from the solution. $\beta$ and energy $E$ are related by the following equation [39]:

$$
E=1 /(2 \beta)^{1 / 2}
$$

Thus, by plotting $\ln \left(q_{e}\right)$ versus $\varepsilon^{2}$, it is possible to obtain the value of $q_{m}$ and $\beta$. The values of $E$ indicate if the adsorption follows an ion exchange mechanism or a physical adsorption mechanism. If $E$ is between 8 and $16 \mathrm{~kJ} \cdot \mathrm{mol}^{-1}$, the process follows ion exchange adsorption, whereas for values of $E<8 \mathrm{~kJ} \cdot \mathrm{mol}^{-1}$, the adsorption process is physical, and if $E>16 \mathrm{~kJ} \cdot \mathrm{mol}^{-1}$ the process is dominated by diffusion intra-particles [40].

\section{Results and Discussion}

\section{Analysis of Design of Experiments}

The arrangements of CCF design include 16 sets of electrocoagulation experiments, including three repetitions for the calculation of the pure error (Table 3 ).

By using multiple regression analysis, the responses were correlated with the three design factors using the second-order polynomial (Eq. (3)). The quadratic regression models for COD $\left(\mathrm{Y}_{1}\right)$ and turbidity $\left(\mathrm{Y}_{2}\right)$ are given by Eq. (13) and Eq. (14), respectively:

$$
\begin{gathered}
\mathrm{Y}_{1}=54.9854-20.6256 \mathrm{X}_{1}-7.71003 \mathrm{X}_{2}- \\
0.926337 \mathrm{X}_{3}+5.34273 \mathrm{X}_{1}^{2}-9.6318 \mathrm{X}_{2}^{2}-6.15411 \mathrm{X}_{3}^{2} \\
-2.76042 \mathrm{X}_{1} \mathrm{X}_{2}+8.8284 \mathrm{X}_{1} \mathrm{X}_{3}+3.24999 \mathrm{X}_{2} \mathrm{X}_{3} \\
\mathrm{Y}_{2}=98.8728+2.37251 \mathrm{X}_{1}+0.609592 \mathrm{X}_{2}+ \\
0.0424751 \mathrm{X}_{3}-1.35475 \mathrm{X}_{1}^{2}+0.368543 \mathrm{X}_{2}^{2}+ \\
0.184353 \mathrm{X}_{3}^{2}-0.0733418 \mathrm{X}_{1} \mathrm{X}_{2}-0.685851 \mathrm{X}_{1} \mathrm{X}_{3}- \\
0.731546 \mathrm{X}_{2} \mathrm{X}_{3}
\end{gathered}
$$

The overall analysis of the models consists in determining the values of the coefficients of determination $\left(R^{2}\right) . R^{2}$ was equal to 0.970 for turbidity (Table 4 ), indicating that $97 \%$ of the variability in the response could be explained by the model. Only $3 \%$ of the total variation cannot be explained by the model. The adjusted determination coefficient $\left(\mathrm{R}_{\text {adj }}^{2}=0.924\right)$ was also satisfactory, confirming the significance of the model. For COD removal, $\mathrm{R}^{2}$ was 0.877 , suggesting an acceptable correlation between the predicted values and the experimental results; this indicates that only $12.3 \%$ of the total variation could not be explained by the empirical model and expresses well enough how quadratic fits to navigate the design space. These values confirm that the equations of the models are reliable. This also indicates that the model terms are significant. The models are also reproducible (values of reproducibility close to 1 ). 
Table 5. Estimated coefficients for COD and Turbidity at coded units.

\begin{tabular}{|c|c|c|c|c|c|c|}
\hline \multirow{2}{*}{ Model term } & \multicolumn{2}{|c|}{ Coefficient estimate } & \multicolumn{2}{c|}{ Standard error } & \multicolumn{2}{c|}{ P-value } \\
\cline { 2 - 7 } & COD & Turbidity & COD & Turbidity & COD & Turbidity \\
\hline const & 54.0331 & 98.873 & 5.5274 & 0.308594 & $6.59169 .10-5$ & $6.23879 \cdot 10^{-14}$ \\
\hline$X_{1}$ & -20.6099 & 2.37274 & 3.59478 & 0.200696 & 0.00122275 & $2.21356 \cdot 10^{-5}$ \\
\hline$X_{2}$ & -7.72926 & 0.608265 & 3.59478 & 0.200696 & 0.0750923 & 0.0230748 \\
\hline$X_{3}$ & -0.93312 & 0.0400998 & 3.59478 & 0.200696 & 0.803867 & 0.848234 \\
\hline$X_{1}^{2}$ & 5.56543 & -1.35637 & 4.65876 & 0.260098 & 0.277314 & 0.00198605 \\
\hline$X_{2}^{2}$ & -9.39469 & 0.368297 & 4.65876 & 0.260098 & 0.0903293 & 0.206534 \\
\hline$X_{3}^{2}$ & -5.91096 & 0.185416 & 4.65876 & 0.260098 & 0.251517 & 0.502696 \\
\hline$X_{1} X_{2}$ & -2.69852 & -0.0758448 & 3.36681 & 0.187969 & 0.453402 & 0.700569 \\
\hline$X_{1} X_{3}$ & 8.76609 & -0.683093 & 3.36681 & 0.187969 & 0.040462 & 0.0109118 \\
\hline$X_{2} X_{3}$ & 3.20216 & -0.731755 & 3.36681 & 0.187969 & 0.378278 & 0.00804916 \\
\hline
\end{tabular}

Plots giving the predicted values versus observed values (Figs. 1 and 2) show that the second-order polynomial models correlate well the experimental results.

In order to test the validity of the models, analysis of variance (ANOVA) was employed to examine the meaning and the adequacy of the models. The results of ANOVA for the quadratic models summarize the analysis of each response and show the significant model terms. Table 4 summarizes ANOVA results for COD and turbidity removals $\left(\mathrm{Y}_{1}\right.$ and $\left.\mathrm{Y}_{2}\right)$.

The significance of each coefficient was evaluated by $\mathrm{p}$ value and standard error (Table 5). A small p-value (less than 0.05 ) indicates that model terms are significant. The analysis of variance reveals that a second-order model adequately fits the experimental data for all responses. For COD removal, it was noted that linear effects of $\mathrm{pH}\left(\mathrm{X}_{1}\right)$, and the interaction term between $\mathrm{pH}$ and reaction time $\left(\mathrm{X}_{1}\right.$ $\left.\mathrm{X}_{3}\right)$ are significant models. Linear effects of $\left(\mathrm{X}_{2}\right),\left(\mathrm{X}_{3}\right)$, the quadratic contribution of $\mathrm{X}_{1}^{2}, \mathrm{X}_{2}^{2}, \mathrm{X}_{3}^{2}$, and the interaction term between $X_{1} X_{2}$ and $X_{2} X_{3}$ does not affect COD removal. However, for turbidity removal it was noticed that the lin- ear effects of $X_{1}$ and $X_{2}$, and the interaction term between $\left(\mathrm{X}_{1} \mathrm{X}_{3}\right)$ and $\left(\mathrm{X}_{2} \mathrm{X}_{3}\right)$ and the quadratic contribution $\mathrm{X}_{1}^{2}$ are significant models. Other coefficients such as $\left(\mathrm{X}_{3}\right), \mathrm{X}_{2}{ }^{2}, \mathrm{X}_{3}{ }^{2}$, and $\mathrm{X}_{1} \mathrm{X}_{2}$ are found to be insignificant.

\section{Effect of Factors on COD and Turbidity Removals}

The own effect of the main factors and their interactions on the responses can be deduced by simulation. Fig. 3 shows the effects of treatment factors and their interactions on COD and turbidity removals from a real pharmaceutical effluent. These effects represent the coefficients in the surface response models (Eqs. (13) and (14)). A coefficient with a plus sign $(+)$ means that the factor has a synergistic effect. By varying the factor the response increases and a minus sign (-) shows an antagonistic effect factor; this suggests that by varying the factor the response decreases. It was noticed that $\mathrm{pH}\left(\mathrm{X}_{1}\right)$, current density $\left(\mathrm{X}_{2}\right)$, and reaction time $\left(\mathrm{X}_{3}\right)$ have negative effects on COD removal, but they have a positive effect on turbidity removal. Decreasing

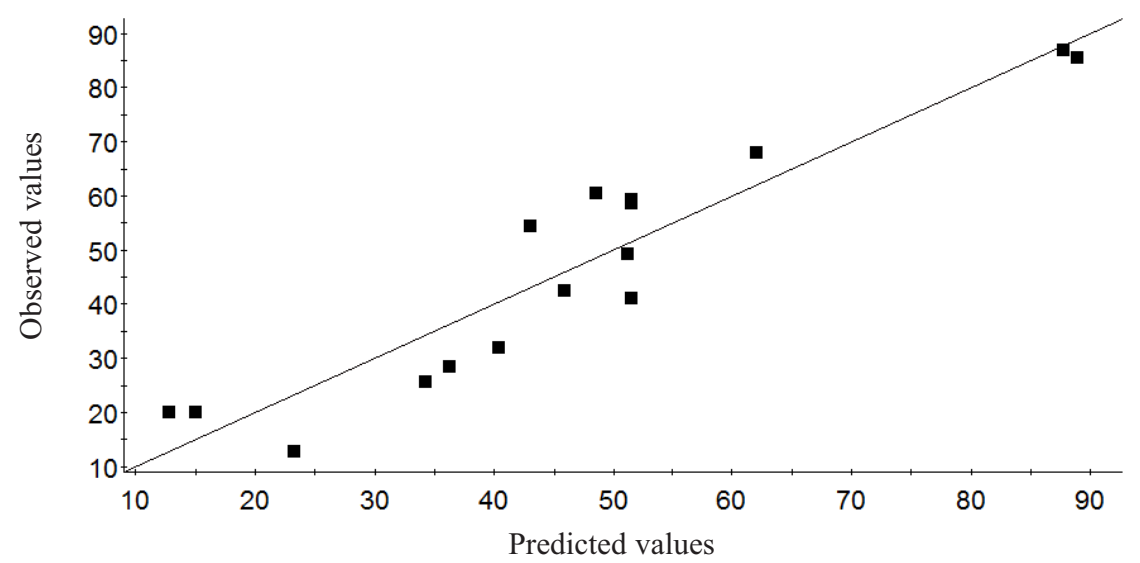

Fig. 1. Plot of experimental versus predicted response for COD. 
Table 6. Run list including factors, responses, iterations, and $\log (\mathrm{D})$.

\begin{tabular}{|c|c|c|c|c|c|c|}
\hline $\mathrm{X}_{1}$ & $\mathrm{X}_{2}$ & $\mathrm{X}_{3}$ & $\mathrm{Y}_{1}$ & $\mathrm{Y}_{2}$ & Iterations & $\log (\mathrm{D})$ \\
\hline $\mathbf{5 . 3 1 9 8}$ & $\mathbf{4 6 . 8 3 0 7}$ & $\mathbf{1 7 . 9 9 9}$ & $\mathbf{7 1 . 5 5 2 4}$ & $\mathbf{9 6 . 5 8 8 5}$ & $\mathbf{1 0 7}$ & $\mathbf{1 . 2 1 4 8}$ \\
\hline 7.8452 & 56.8553 & 16.4135 & 37.2042 & 100.280 & 52 & 1.4320 \\
\hline 5.1193 & 47.4077 & 17.6579 & 74.2346 & 96.204 & 77 & 1.2479 \\
\hline 7.8398 & 56.9669 & 16.4040 & 37.1555 & 100.284 & 74 & 1.4327 \\
\hline 7.8773 & 53.1551 & 17.7981 & 41.1595 & 100.003 & 69 & 1.3750 \\
\hline 4.3365 & 49.8461 & 16.3348 & 85.7902 & 94.4979 & 59 & 1.4342 \\
\hline 4.3515 & 49.249 & 16.2904 & 85.7672 & 94.5021 & 56 & 1.4337 \\
\hline 7.8431 & 56.9386 & 16.4565 & 37.2184 & 100.279 & 54 & 1.4318 \\
\hline
\end{tabular}

Values in bold correspond to the values in which $\log (\mathrm{D})$ (distance $\mathrm{d}$ to target) is at the smallest value.

in initial $\mathrm{pH}$, current density, and reaction time result in increasing COD removal, but there was little effect on turbidity removal percentage. It was observed that the interaction terms $\mathrm{X}_{1} \mathrm{X}_{3}$ and $\mathrm{X}_{2} \mathrm{X}_{3}$ have a positive effect on COD removal, but a negative effect on turbidity removal. Unlike the interaction term, $\mathrm{X}_{1} \mathrm{X}_{2}$ have a negative effect on both $\mathrm{COD}$ and turbidity removals. The second-order terms $\mathrm{X}_{1}^{2}$ have a negative effect on COD and a positive effect on turbidity removal. Finally, the second-order terms $\mathrm{X}_{2}^{2}$ and $\mathrm{X}_{3}^{2}$ have a negative effect on COD but a positive effect on turbidity removal.

In order to investigate the interactions between different independent variables and their corresponding effects on the responses, contour plots were drawn (Figs. 4-6). The contour plot is a graphical representation of a three-dimensional response surface as a function of two independent variables, maintaining all other variables at a fixed level. These plots can be helpful in understanding both the main and interaction effects of the independent variables on the responses. Fig. 4 shows the effects of $\mathrm{pH}$ and current density on COD and turbidity removals, reaction time was maintained constant at central value $(20 \mathrm{~min})$. The effect of $\mathrm{pH}$ can be explained considering aluminum and antibiotics (tetracycline and b-lactam derivatives) equilibrium related to the $\mathrm{pH}$ values. It was noted that high COD removal was found at $\mathrm{pH} \leq 5$, and a current density between 20 and 65
$\mathrm{mA} / \mathrm{cm}^{2}$. The increase in COD removal at this level of $\mathrm{pH}$ can be explained by the transformation of $\mathrm{Al}^{3+}$ into soluble monomeric species such as $\mathrm{Al}(\mathrm{OH})^{2+}$ and $\mathrm{Al}(\mathrm{OH})_{2}^{+}$in acid medium, and $\mathrm{Al}(\mathrm{OH})_{4}^{-}$in alkaline medium.

These species are converted into insoluble $\mathrm{Al}(\mathrm{OH})_{3}$ flocs by complex precipitation kinetics. Freshly formed amorphous $\mathrm{Al}(\mathrm{OH})_{3}$ can absorb ions and even soluble organic compounds and/or trap colloidal particles, which then coagulate to produce particles that precipitate, usually near neutral $\mathrm{pH}$. It is important to note that under acidic conditions $(\mathrm{pH}<3)$, penicillins undergo isomerization linked to the breakdown of the beta-lactam ring and the formation of the imidazoline ring, turning into penillic acids and $\mathrm{TC}$ exists as $\mathrm{TCH}_{3}^{+}$.

At $\mathrm{pH}$ between 3.3 and 7, $\mathrm{TC}$ exists as $\mathrm{TCH}_{2}^{ \pm}$, due to the loss of proton from the phenolic diketone moiety. At $\mathrm{pH} \geq 10$, where $\mathrm{TC}$ presents as $\mathrm{TC}^{2-}$ and penicillin is in the anionic form, $\mathrm{Al}(\mathrm{OH})_{4}^{-}$is dominant and consequently the coagulation rapidly decreases [19, 40-44]. However, the effects of $\mathrm{pH}$ and current density on turbidity removal are not important because there was not a remarkable change in the elimination rate of turbidity $(\approx 93-100 \%)$. This result can be explained by the low variation of turbidity of pharmaceutical effluents.

The effects of $\mathrm{pH}$ and time reaction are shown in Fig. 5. Current density was kept constant at central value $(i=50$

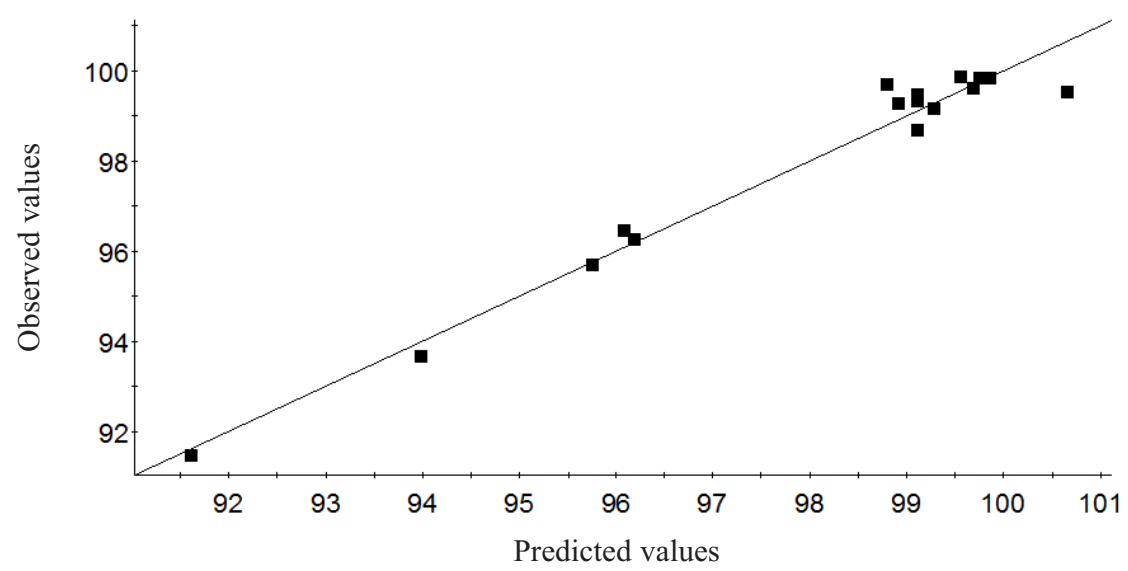

Fig. 2. Plot of experimental versus predicted response for turbidity. 
Table 7. Isotherm constants for adsorption of COD.

\begin{tabular}{|c|c|c|c|c|}
\hline \multirow{2}{*}{ Freundlich } & $K_{f}(\mathrm{mg} / \mathrm{L})$ & \multicolumn{2}{|c|}{$\mathrm{n}$} & $\mathrm{R}^{2}$ \\
\cline { 2 - 5 } & 0.0059 & \multicolumn{2}{|c|}{0.577} & 0.972 \\
\hline $\begin{array}{c}\text { Dubinin- } \\
\text { Radushkevich }\end{array}$ & $Q_{m}(\mathrm{mg} / \mathrm{L})$ & $B(\mathrm{~kJ} / \mathrm{mol})$ & $E(\mathrm{~kJ} / \mathrm{mol})$ & $\mathrm{R}^{2}$ \\
\cline { 2 - 5 } & 306.12 & 0.013 & 0.0062 & 0.901 \\
\hline
\end{tabular}

$\mathrm{mA} / \mathrm{cm}^{2}$ ). From the contour plot it was noticed that COD removal took maximum values if initial $\mathrm{pH}$ was maintained fewer than 5 and time treatment between 10 and $22 \mathrm{~min}$. For these conditions, turbidity varied slightly and we didn't notice important effects.

In order to investigate the effect of current density and time reaction on COD and turbidity removals, experiments were conducted at $\mathrm{pH}=7$ under different operating times and current densities. The results are presented in Fig. 6, where the contours clearly show an optimum zone of COD removal at a current density between 32.3 and $42.9 \mathrm{~mA} / \mathrm{cm}^{2}$ and time treatment between 17.4 and $21.8 \mathrm{~min}$. COD removal decreases with increasing current density beyond $50 \mathrm{~mA} / \mathrm{cm}^{2}$. It is well known that EC is strongly affected by the current density [45]. This effect can be explained by the fact that an increase in anodic dissolution of aluminum occurs with high current density, which results in the formation of high amounts of precipitate for the removal of pollutants. Furthermore, the rate of production of hydrogen bubbles increases and their sizes decrease as the current density increases. All these effects are beneficial for effective removal of pollutants. Operating at high current densities may cause other side reactions in the vicinity of the anode, such as the direct oxidation of one of the constituents of the contaminant or the formation of oxygen, which limits the effectiveness of electrocoagulation. Conversely, a high current density causes passivity of the cathode by reduction, leading to a high consumption of energy by the Joule effect. It would be interesting to work on slightly high current densities. From a consumer perspective, especially regarding energy and electrode consumptions, the best conditions correspond to a low current density and an important electrolysis time. To overcome the unnecessary generation of $\mathrm{Al}(\mathrm{OH})_{3}$ in wastewater, it is ultimately important to avoid working at too high current densities and set to i values less than $50 \mathrm{~mA} / \mathrm{cm}^{2}$. The efficiency of contaminant reduction depends on $\mathrm{Al}$ (III) production by the anode so that high electrolysis duration would cause higher production of these aluminum hydroxide, which are in turn responsible for the coagulation process. As shown in Table 3, COD and turbidity removals also increased as a function of time, and after $22 \mathrm{~min}$ of electrolysis no efficacy changes are observed as the EC duration is increased.

\section{Optimization}

The main objective of optimization is to determine the optimum parameters for COD and turbidity removal during the process of electrocoagulation. To control the optimization criteria the weight function has a key role, as well as reasonable limits and targets for the responses. The optimizer of the Modde software uses a Nelder Mead Simplex method with the fitted response functions to optimize an overall desirability function combining the individual desirability of each response. The shape of the desirability function is controlled by the weight and the settings of criteria (Min, Target, Max) for each response.

For each optimum found, the software provides the optimal values of input factors, the response values predicted by the model, the number of iterations until the optimum, and the logarithm of the overall distance to the target named as $\log (\mathrm{D})$.

The "overall distance to target," $\mathrm{D}$, is computed by the following equation [46]:

$$
\mathrm{D}=\log _{10}\left[\left(\sum\left(w i((y i-T) /(T-L))^{2}\right)\right) / M\right]
$$

...where $w_{i}$ is the assigned weight representing the importance of the response, $y_{i}$ is the response to be maximized or minimized, $T$ is the user-desired target, $L$ is the user-defined worst acceptable response value, and $M$ is the number of responses. a)

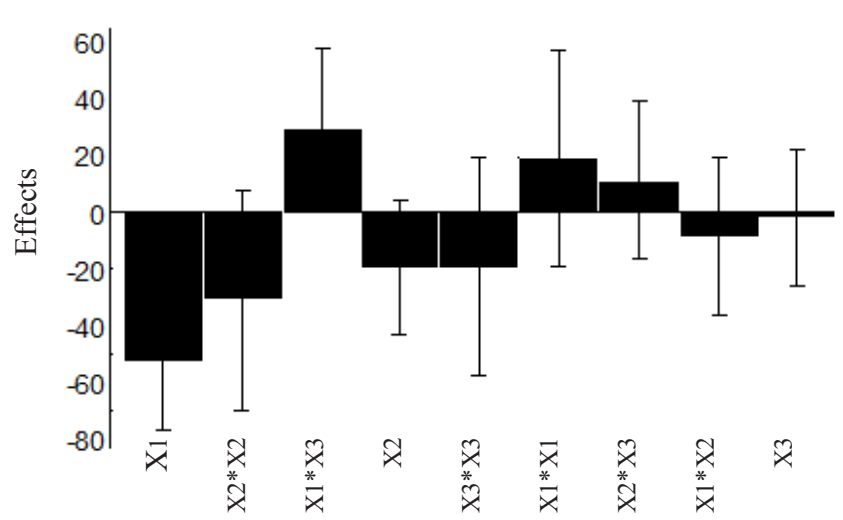

b)

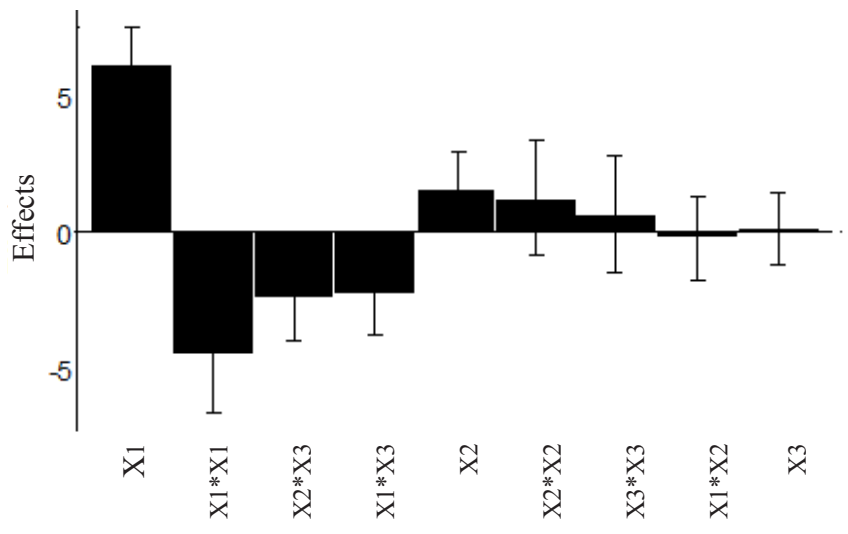

Fig. 3. Factors effects for (a) COD removal; (b) turbidity removal. 
A maximum overall desirability function results in a minimum $\log (\mathrm{D})$. For optimization, $\mathrm{D}$ is not used but it is displayed as $\log (\mathrm{D})$ in the run list. When $\log (\mathrm{D})=0$, all responses are between the target and the specified acceptable limit. $\log (\mathrm{D})$ becomes negative when the values of all responses are still closer to the target. The value of $\mathrm{D}$ is equal to -10 when all responses have reached $T$.
Fig. 7 displays, for each simplex, the value of $\log (\mathrm{D})$ vs. iteration number. The target and acceptable limit(s) are drawn for every response as lines (Fig. 8). It was noticed that not all responses are between the target and acceptable limit, but some are between the min and the target.

Table 6 shows the run list, which includes the factors, responses, iterations, and $\log (\mathrm{D})$. After running the opti-
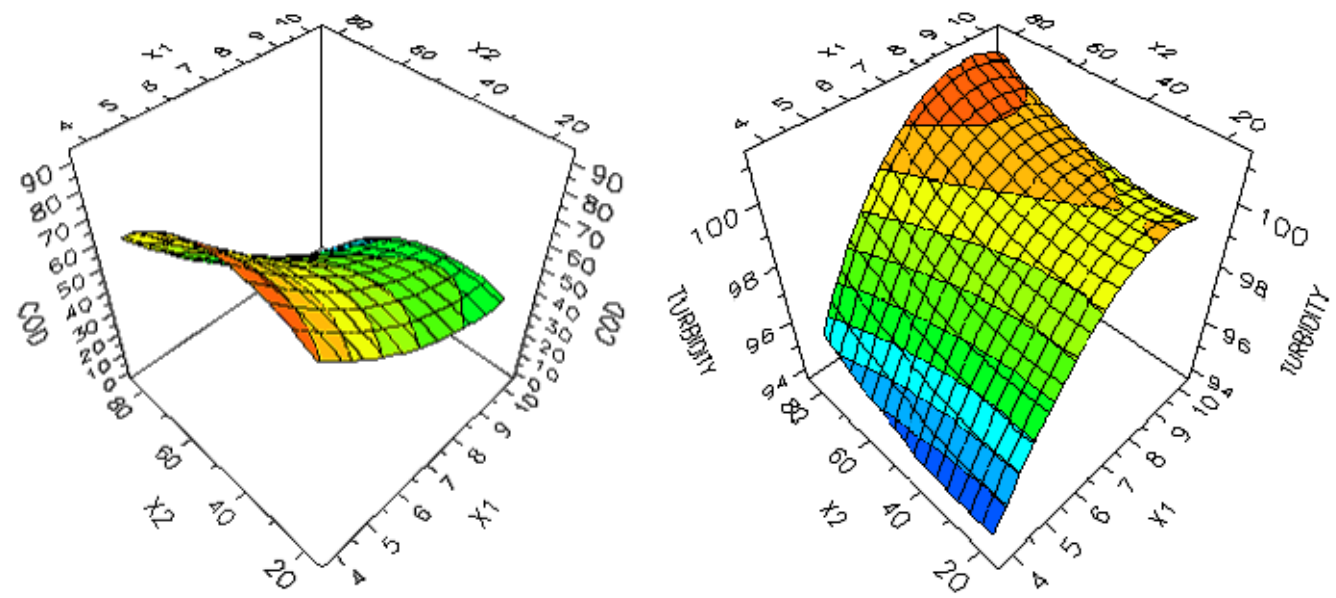

Fig. 4. Effects of $\mathrm{pH}$ and current density on $\mathrm{COD}$ and turbidity removal.
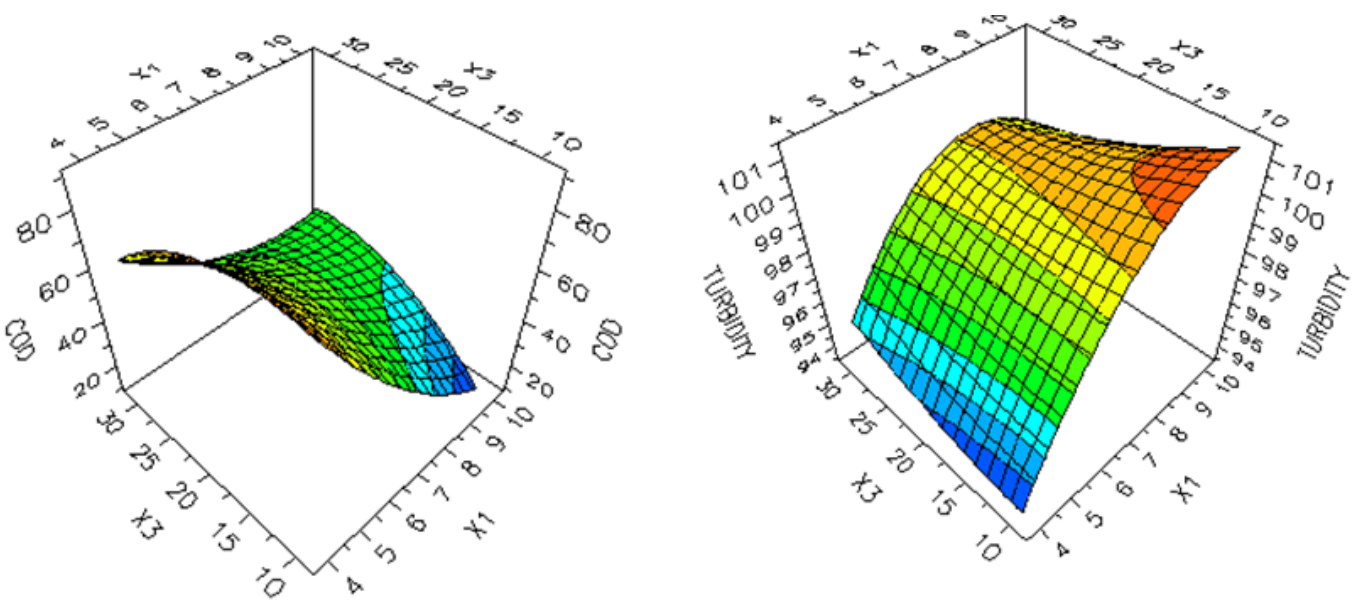

Fig. 5. Effects of $\mathrm{pH}$ and reaction time on COD and turbidity removal.
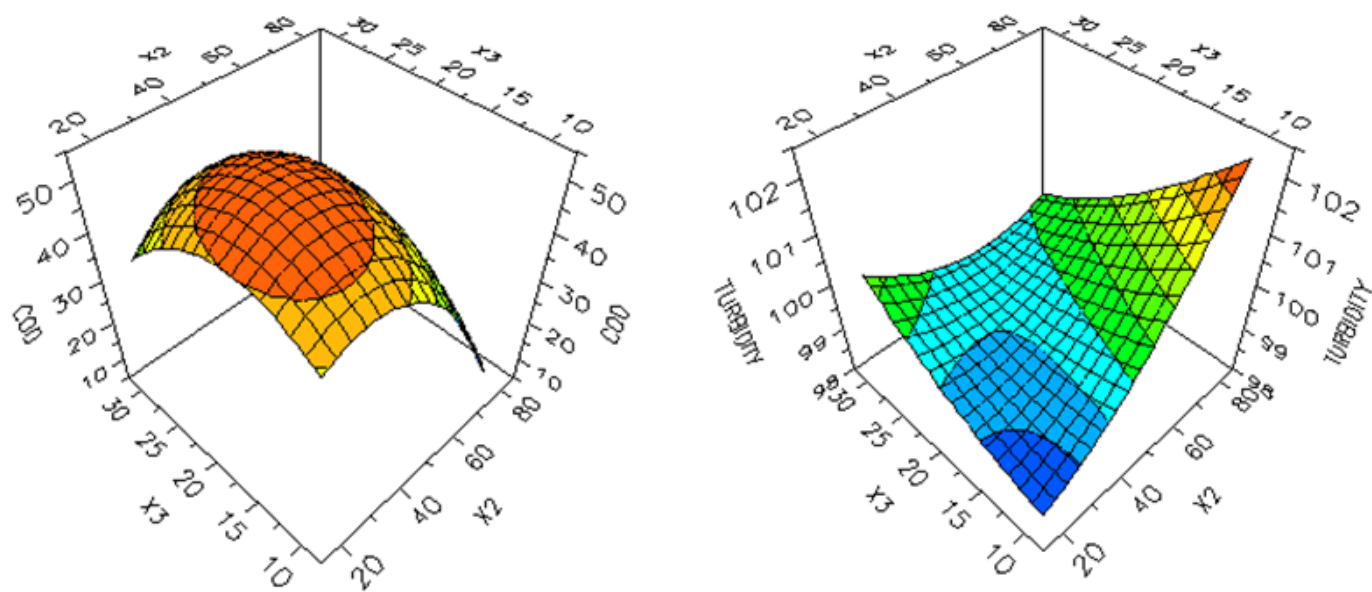

Fig. 6. Effects of current density and reaction time on COD and turbidity removal. 


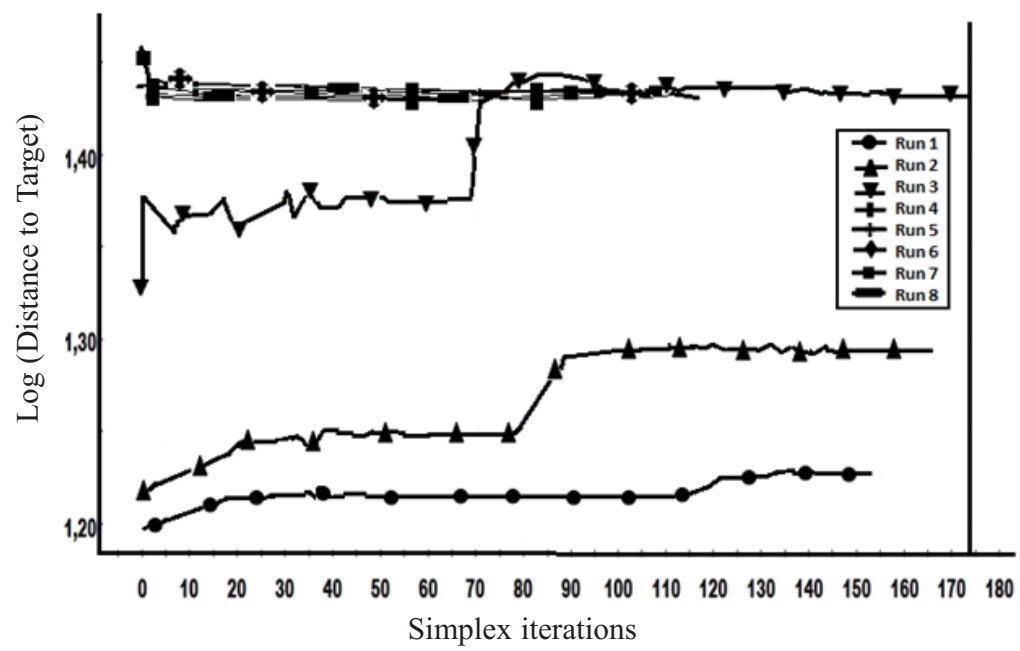

Fig. 7. Values of $\log (\mathrm{D}) v s$. iteration number for each simplex.

mizer for the best proposal, lowest $\log (\mathrm{D})$ is selected. In the run list above, row 1 has the lowest $\log (\mathrm{D})$ (iteration 107), meaning that row 1 is preferable. The optimal parameters for COD and turbidity are $\mathrm{pH}=5.31$, current density $=46.83 \mathrm{~mA} / \mathrm{cm}^{2}$, and reaction time $=17.99 \mathrm{~min}$.

These obtained results were compared with those deduced from the contour plots. At optimal conditions, COD and turbidity removals are $70.8 \%$ and $96.7 \%$, respectively. These results are close to those estimated by the optimizer software.

In order to confirm the validity of the statistical experimental strategies, experiments under optimal conditions were realized. The average measured COD and turbidity removals are respectively equal to 75.64 and $96.34 \%$. This experimental validation proved that the developed models could be considered to be accurate and reliable.

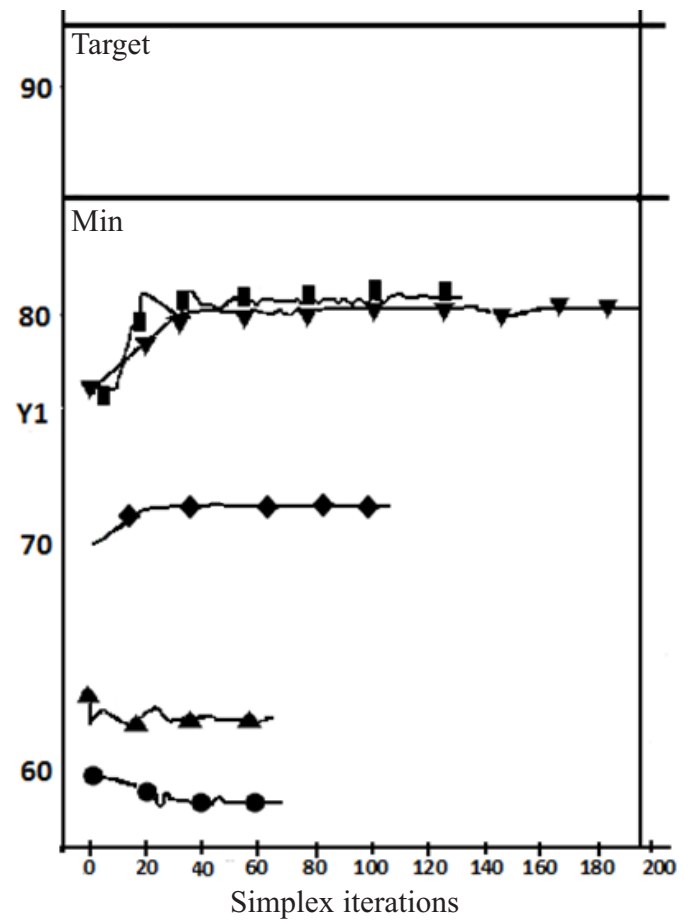

Fig. 8. COD and turbidity removals vs. iterations plots.

\section{Isotherm Modeling}

To investigate the equilibrium isotherms of adsorption in term of COD, four experiments were taken from the experimental design matrix. Freundlich and Dubinin-Raduskovich parameters for COD removal are summarized in Table 7. Freundlich adsorption capacity was found to be 0.0059 $\mathrm{L} / \mathrm{mg}$. From the linear plot of the Dubinin-Raduskovich model, qm was determined and its value is about 306.12 $\mathrm{mg} / \mathrm{g}$. The mean free energy $(E)$ is equal to $0.0062 \mathrm{~kJ} / \mathrm{mol}$. This value indicates that the process of adsorption is a physisorption process and that the van der Waals forces are predominant. These results are in agreement with the mechanism of electrocoagulation. It is generally assumed that in the electrocoagulation process, the coagulation is provoked essentially by the reduction of the net surface area charge

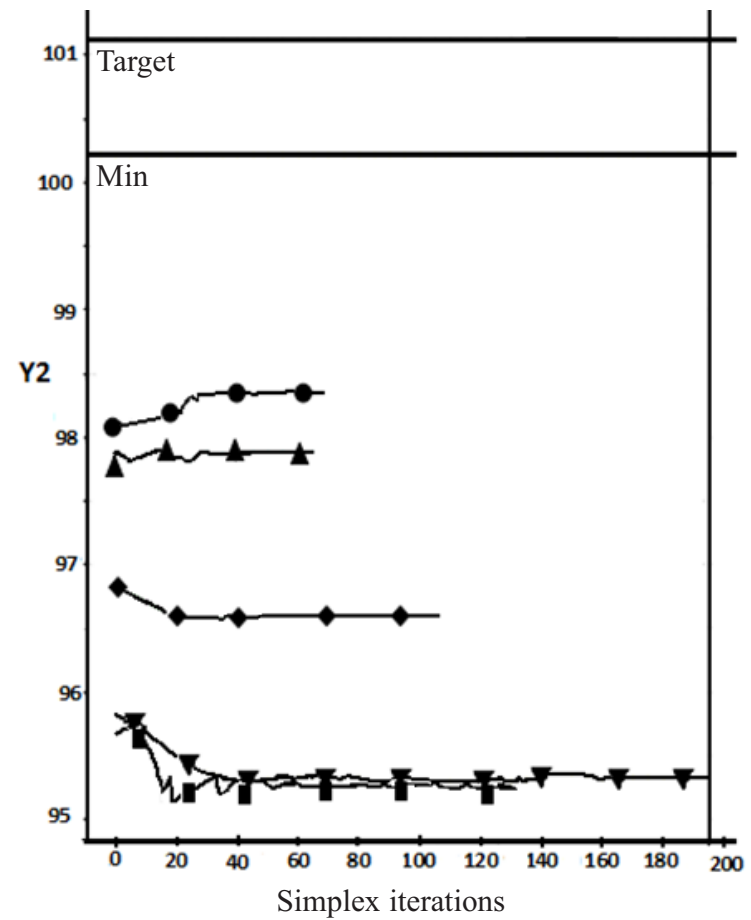




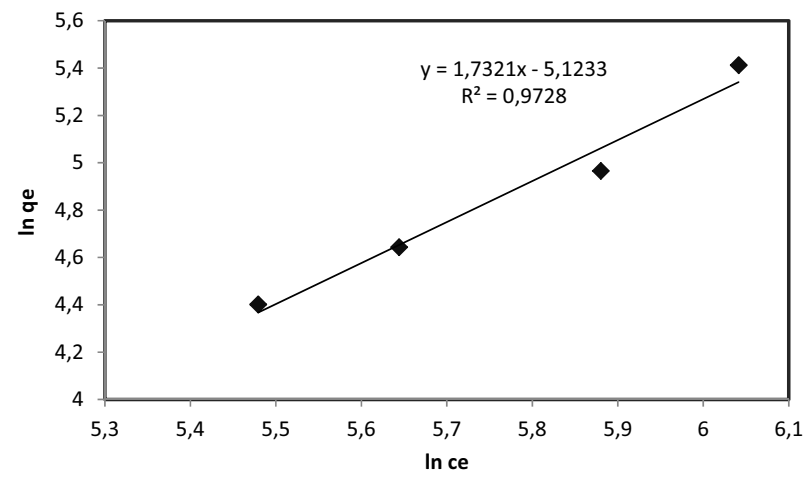

Fig. 9. Freundlich isotherm adsorption.

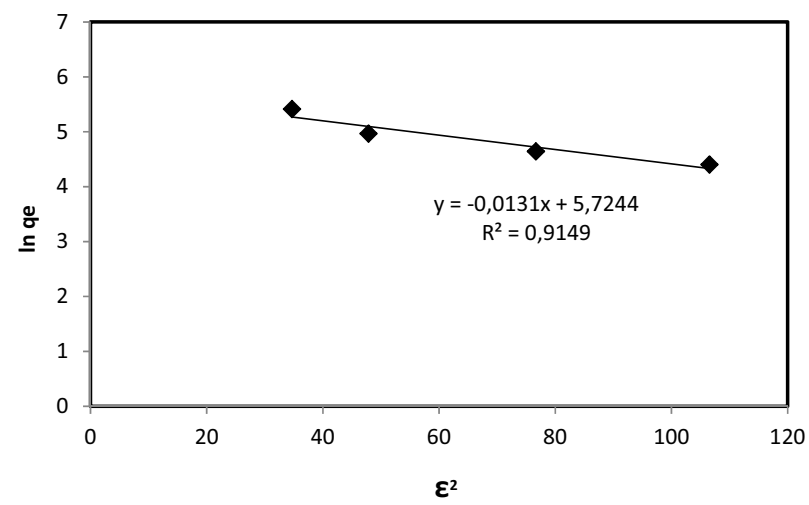

Fig. 10. Dubinin-Radushkevich isotherm adsorption.

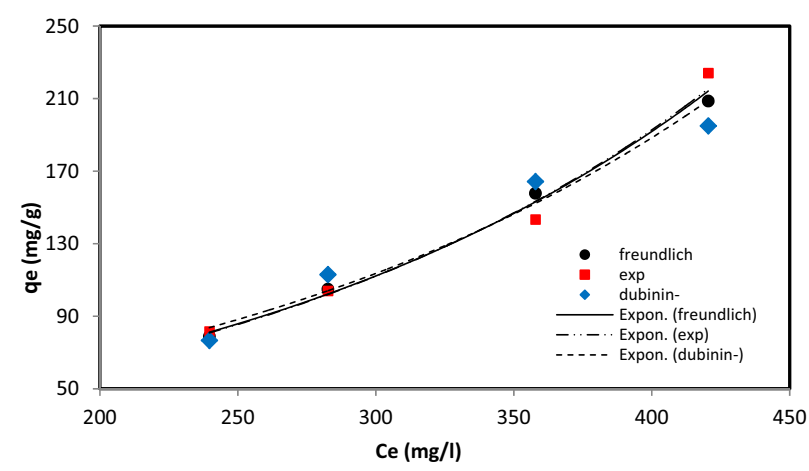

Fig. 11. Experimental, Freundlich, and Dubinin-Radushkevich model values of $q_{e}$ versus $C_{e}$. until the colloidal particles, previously stabilized by electrostatic repulsion, can get closer to the van der Waals forces to hold them together and allow aggregation. Figs. 9 and 10 show that the COD experimental measurements give a good fit for the Freundlich isotherm model with a good linear regression coefficient $\left(\mathrm{R}^{2}=0.972\right)$, and an acceptable fit for the Dubinin-Raduskovich isotherm $\left(\mathrm{R}^{2}=0.914\right)$. However, the Freundlich isotherm seems to be better than the DubininRaduskovich isotherm. It can be concluded that the nature of the aluminum surface is more heterogeneous.

The experimental results plotted against the DubininRaduskovich and Freundlich adsorption isotherms are shown in Fig. 11. Comparison of the results reveals that the Freundlich adsorption isotherm was the best model for COD adsorption. Hence the values predicted by the Freundlich model are close to the experimental data for the values of $C_{e}$ less than $300 \mathrm{mg} / \mathrm{L}$, whereas at higher values of $C_{e}$ this model shows little difference compared to the experimental data.

\section{Operating Cost}

Variations of the operating costs for the treatment of pharmaceutical wastewater are presented in Fig. 12. When the current density enhanced from 20 to $80 \mathrm{~mA} / \mathrm{cm}^{2}$ and reaction time from 10 to $30 \mathrm{~min}$, electrode consumption was enhanced from 0.02471536 to $0.49721484 \mathrm{~kg} / \mathrm{m}^{3}$ and energy consumption enhanced from 0.7366 to 37.2968 $\mathrm{kWh} / \mathrm{m}^{3}$. It was noticed that the maximum operating cost was found to be equal to $2.8289 \mathrm{US} \$ / \mathrm{m}^{3}$, which corresponds to a current density of $80 \mathrm{~mA} / \mathrm{cm}^{2}$ and electrolysis time of $30 \mathrm{~min}$. This is caused by the increase in the rate of dissolution of the metal and the high level of energy consumption. The minimum operating cost was observed at a current density of $20 \mathrm{~mA} / \mathrm{cm}^{2}$ and electrolysis time of 10 $\mathrm{min}$, which was equal to $0.1053 \mathrm{US} \$ / \mathrm{m}^{3}$. This corresponds to low metal dissolution and low consumption energy. According to these results, there is a direct relationship between current density, electrolysis time, and operating cost. This cost increases with increasing current density, electrolysis time, and vice versa. The energy consumption is affected by the charge loading $(Q=I \cdot t)$ and electrolysis potential. A higher charge loading will increase energy and electrode consumption. Charge loading is very important

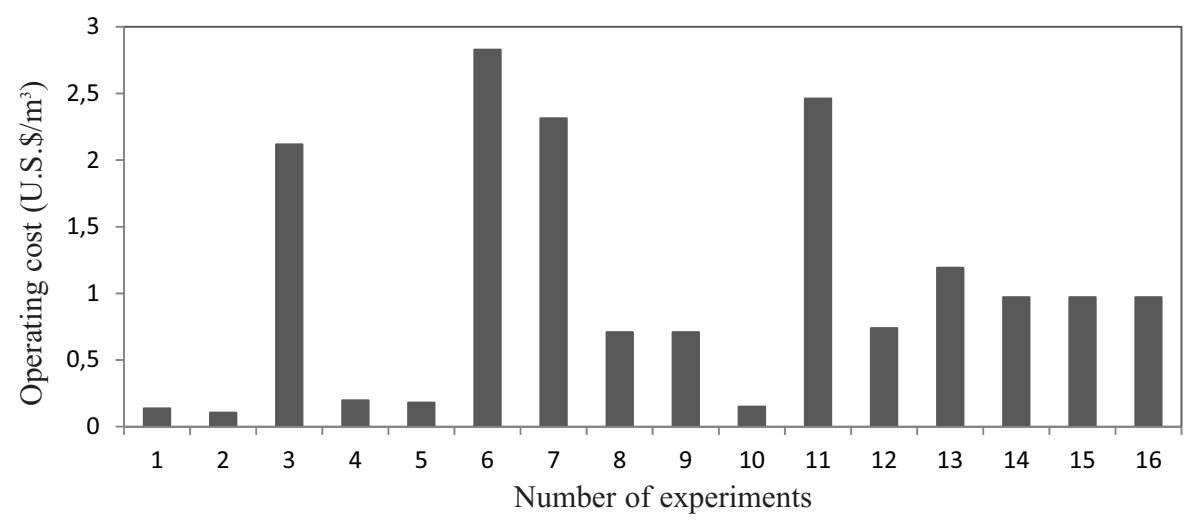

Fig. 12. Evolution of operating cost in the experiments of electrocoagulation treatment. 
for the electrocoagulation process, which depends on influent property and effluent quality. Under optimal conditions the general cost was found to be $0.8113 \mathrm{US} \$ / \mathrm{m}^{3}$. This result showed that the EC process for the treatment of pharmaceutical effluent under optimum conditions is quite economical. This result is in agreement with Ozyonar and Karagozoglu [47].

\section{Conclusions}

In the present work the electrocoagulation process was used for the treatment of a pharmaceutical wastewater using aluminum electrodes. A full factorial central composite face-centered (CCF) design was successfully employed for the experimental design and analysis of results.

This study clearly showed that RSM was one of the suitable methods to optimize the operating conditions and maximize COD and turbidity removal. The obtained correlation coefficient $\mathrm{R}^{2}$ was found equal to 0.97 for $\mathrm{COD}$ and 0.877 for turbidity removal, indicating that the actual data fit quite well with the predicted data by applying the quadratic models. The effects of $\mathrm{pH}$, current density, and electrolysis time on optimal operational conditions were evaluated. The optimum of turbidity and COD removal efficiencies were found at initial $\mathrm{pH}$ of 5.31, current density of $46.83 \mathrm{~mA} / \mathrm{cm}^{2}$ and reaction time of $17.99 \mathrm{~min}$. The corresponding removal efficiencies in optimum conditions were found equal to $70.8 \%$ and $96.7 \%$ for COD and turbidity removal, respectively.

Experimental data were modeled using adsorption isotherms. Comparison of results revealed that the Freundlich isotherm $\left(\mathrm{R}^{2}=0.972\right)$ was better suited than the Dubinin-Raduskovich model $\left(\mathrm{R}^{2}=0.914\right)$. The mode of adsorption is a physisorption with heterogeneous aluminum surface. Under optimal conditions, the operating cost was found equal to $0.8113 \mathrm{US} \$ / \mathrm{m}^{3}$, which can be considered an economical process.

\section{References}

1. LATEEF A. The microbiology of pharmaceutical effluent and its public implications. World J. Microbiol. Biotechnol. 20, 167, 2004.

2. DAUGHTON C.G., TERNES T.A, Pharmaceuticals and personal care products in the environment: agents of subtle change. Environ. Health. Perspect. 107, 907, 1999.

3. GROS M., PETROVIC M., BARCELÓ D. Wastewater treatment plants as a pathway for aquatic contamination by pharmaceuticals in the Ebro river basin (northeast Spain). Environ. Toxicol. Chem. 26, 1553, 2007.

4. SANTOS J.L., APARICIO I., ALONSO E. Occurrence and risk assessment of pharmaceutically active compounds in wastewater treatment plants. A case study: Seville city (Spain). Environ. Int. 33, 596, 2007.

5. TEKIN H., BILKAY O., ATABERK S.S., BALTA T.H., CERIBASI I.H. , SANIN F.D., DILEK F.B., YETIS U. Use of Fenton oxidation to improve the biodegradability of a pharmaceutical wastewater. J. Hazard. Mater. B 136, 258, 2006.
6. RAJ D.S.S., ANJANEYULU A. Evaluation of biokinetic parameters for pharmaceutical wastewaters using aerobic oxidation integrated with chemical treatment. Process. Biochem. 40, 165, 2005.

7. DEEGAN A.M., SHAIK B., NOLAN K., URELL K., OELGEMÖLLER M., TOBIN J., MORISSEY A. Treatment options for wastewater effluents from pharmaceutical companies. Int. J. Environ. Sci. Technol. 8, 649, 2011.

8. SREEKANTH D., SIVARAMAKRISHNA D., HIMABINDU H., ANJANEYULU Y. Thermophilic treatment of bulk drug pharmaceutical industrial wastewaters by using hybrid up flow anaerobic sludge blanket reactor. Bioresource. Technol. 100, 2534, 2009.

9. SNYDER S., ADHAM S., REDDING A., CANNON F., DECAROLIS J., OPPENHEIMER J., WERT E., YOON Y. Role of membranes and activated carbon in the removal of endocrine disruptors and pharmaceuticals. Desalination 202, 156, 2007.

10. ANDREOZZI R., CAPRIO V., MAROTTA R. VOGNA D. Paracetamol oxidation from aqueous solutions by means of ozonation and $\mathrm{H}_{2} \mathrm{O}_{2} / \mathrm{UV}$ system. Wat. Res. 37, 993, 2003.

11. CHEN G. Electrochemical technologies in wastewater treatment. Sep. Purif. Technol. 38, 11, 2004.

12. WANG C.T., CHOU W.L., KUO Y.M. Removal of COD from laundry wastewater by electrocoagulation/electroflotation. J. Hazard. Mater. 164, 81, 2009.

13. GENGEC E., KOBYA M., DEMIRBAS E., AKYOL A., OKTOR K. Optimization of baker's yeast wastewater using response surface methodology by electrocoagulation. Desalination 286, 200, 2012.

14. DO J.S., CHEN M.L. Decolourization of dye-containing solutions by electrocoagulation. J. Appl. Electrochem. 24, 785, 1994.

15. HU C.Y., LO S.L., KUAN W.H. Effects of co-existing anions on fluoride removal in electrocoagulation (EC) process using aluminium electrodes. Wat. Res. 37, 4513, 2003.

16. LARUE O., VOROBIEV E., DURAND C.V.B. Electrocoagulation and coagulation by iron of latex particles in aqueous suspensions. Sep. Purif. Technol. 31, 177, 2003.

17. JAIN R., SHARMA N., RADHAPYARI K. Electrochemical treatment of pharmaceutical azo dye amaranth from waste water. J Appl Electrochem. 39, 577, 2009.

18. DOMÍNGUEZ J. R., GONZÁlEZ T., PALO P., SÁNCHEZ-MARTÍN J., RODRIGO M. A., SÁEZ C. Electrochemical degradation of a real pharmaceutical effluent. Water Air Soil Pollut. 223, 2685, 2012.

19. BRILLAS E., SIRÉS I. Electrochemical remediation technologies for waters contaminated by pharmaceutical residues, in: LICHTFOUSE E., SCHWARZBAUER J., ROBERT D. Environmental chemistry for a sustainable world. Volume 2: Remediation of Air and Water Pollution, pp. 297-346, 2012.

20. FARHADI S., AMINZADEH B., TORABIAN A., KHATIBIKAMAL V., ALIZADEH FARD M. Comparison of COD removal from pharmaceutical wastewater by electrocoagulation, photoelectrocoagulation, peroxi-electrocoagulation and peroxi-photoelectrocoagulation processes. J. Hazard. Mater. 219-220, 35, 2012.

21. BOROSKI M., RODRIGUES A. C., GARCIA J. C., SAMPAIO L.C., NOZAKI1 J., HIOKA N. Combined electrocoagulation and $\mathrm{TiO}_{2}$ photoassisted treatment applied to wastewater effluents from pharmaceutical and cosmetic industries. J. Hazard. Mater. 162, 448, 2009. 
22. MONTGOMERY D.C. Design and Analysis of Experiments, $7^{\text {th }}$ ed.; John Wiley and Sons, New York, 2008.

23. KALIL S.J., MAUGERI F., RODRIGUES M.I. Response surface analysis and simulation as a tool for bioprocess design and optimization. Process Biochem. 35, 539, 2000.

24. DESAI K.M., SURVASE S.A., SAUDAGAR P.S., LELE S.S., SINGHAL R.S. Comparison of artificial neural network (ANN) and response surface methodology (RSM) in fermentation media optimization: Case study of fermentative production of scleroglucan. Biochem. Eng. J. 41, 266, 2008.

25. IMANDI S.B., BANDARU V.V.R., SOMALANKA S.R., BANDARU S.R., GARAPATI H.R. Application of statistical experimental designs for the optimization of medium constituents for the production of citric acid from pineapple waste. Bioresource Technol. 99, 4445, 2008.

26. NASRULLAHA M., SINGH L., WAHID Z.A. Treatment of sewage by electrocoagulation and the effect of high current density. Energy Environ. Eng. J. 1, 27, 2012.

27. ARSLAN-ALATON I., KABDAS I., VARDAR B., TUNAY O. Electrocoagulation of simulated reactive dyebath effluent with aluminum and stainless steel electrodes. J. Hazard. Mater. 164, 1586, 2009.

28. BHATTI M.S., KAPOOR D., KALIA R.K., REDDY A.S., THUKRAL A.K. RSM and ANN modeling for electrocoagulation of copper from simulated wastewater: Multi objective optimization using genetic algorithm approach. Desalination 274, 74, 2011

29. GHOSH D., MEDHI C.R., PURKAIT M.K. Treatment of fluoride containing drinking water by electrocoagulation using monopolar and bipolar electrode connections. Chemosphere 73, 1393, 2008.

30. DROUICHE N., GHAFFOUR N., LOUNICI H., MAMERI N. Electrocoagulation of chemical mechanical polishing wastewater. Desalination 214, 31, 2007.

31. MARY N., CARROLL C., WILL G., Engineering Statistics Handbook. Statistical Engineering Division, NIST, pp. 968973. 2003.

32. SLEIMANA M., VILDOZO D., FERRONATO C., CHOVELON J.M. Photocatalytic degradation of azo dye Metanil Yellow: Optimization and kinetic modeling using a chemometric approach. Appl. Catal. B-Environ. 77, 1, 2007.

33. ALEBOYEH A., DANESHVAR N., KASIRI M.B. Optimization of C.I. Acid Red 14 azo dye removal by electrocoagulation batch process with response surface methodology. Chem. Eng. Prog. 47, 827, 2008.

34. BEZERRAA M.A., SANTELLI R.E., OLIVEIRA E.P.,
VILLAR L.S., ESCALEIRA L.A. Response surface methodology (RSM) as a tool for optimization in analytical chemistry. Talanta 76, 965, 2008.

35. BAS D., BOYACI I.H. Modeling and optimization I: Usability of response surface methodology. J. Food Eng. 78, 836, 2007.

36. BOULINGUIEZ B., BOUZAZA A., MERABET I., WOLBERT D. Photocatalytic degradation of ammonia and butyric acid in plug-flow reactor: Degradation kinetic modeling with contribution of mass transfer. J. Photochem. Photobiol. A 200, 254, 2008.

37. KAVITHA D., NAMASIVAYAM C. Experimental and kinetic studies on methylene blue adsorption by coir pith carbon. Bioresource Technol. 98, 14, 2007.

38. DABROWSKI A. Adsorption-from theory to practice. Adv. Colloid Interf. Sci. 93, 135, 2001.

39. ÖZCAN A., SAFA ÖZCAN A. Adsorption of Acid Red57 from aqueous solutions onto surfactant-modified sepiolite. J. Hazard. Mater. 125, 252, 2005.

40. XU J., HE Y., ZHANG Y., GUO C., LI L., WANG Y. Removal of sulfadiazine from aqueous solution on kaolinite. Front. Environ. Sci. Eng. 7, (6), 836, 2013.

41. AIT OUAISSA Y., CHABANI M., AMRANE A., BENSMAILI A. Removal of tetracycline by electrocoagulation: Kinetic and isotherm modeling through adsorption. J. Environ. Chem. Eng. 2, 177, 2014.

42. MERZOUK B., GOURICH B., SEKKI A., MADANI K., VIAL CH., BARKAOUI M. Studies on the decolorization of textile dye wastewater by continuous electrocoagulation process. Chem. Eng. J. 149, 207, 2009.

43. GHERNAOUT D., GHERNAOUT B., SAIBA A., BOUCHERIT A., KELLIL A. Removal of humic acids by continuous electromagnetic treatment followed by electrocoagulation in batch using aluminium electrodes. Desalination 239, 295, 2009.

44. LI Z., SCHULZ L., ACKLEY C., FENSKE N. Adsorption of tetracycline on kaolinite with $\mathrm{pH}$-dependent surface charges. J. Colloid Interf. Sci. 351, 254, 2010.

45. VASUDEVAN S., LAKSHMI J., SOZHAN G. Optimization of electrocoagulation process for the simultaneous removal of mercury, lead, and nickel from contaminated water. Environ. Sci. Pollut. Res. Int. 19, 2734, 2011.

46. MONTGOMERY D.C. Design and Analysis of Experiments, $5^{\text {th }}$ ed.; John Wiley and Sons, New York, 2000.

47. OZYONAR F., KARAGOZOGLU B. Operating cost analysis and treatment of domestic wastewater by electrocoagulation using aluminum electrodes, Pol. J. Environ. Stud. 20, (1), 173, 2011. 
